Research Article

\title{
Effect of the Dynamic Load on Stresses in a Deck Pavement with an Interlayer Contact Model
}

\author{
Xuntao Wang $\left(\mathbb{D}\right.$, Jianhu Feng $\mathbb{D}^{\mathbb{D}}$, Hu Wang, Shidi Hong, Xiaohan Cheng, and Supei Zheng \\ School of Science, Chang'an University, Xi'an, China \\ Correspondence should be addressed to Xuntao Wang; wxt5288@126.com and Jianhu Feng; jhfeng@chd.edu.cn
}

Received 3 April 2018; Accepted 9 May 2018; Published 19 June 2018

Academic Editor: Chiara Bedon

Copyright (C) 2018 Xuntao Wang et al. This is an open access article distributed under the Creative Commons Attribution License, which permits unrestricted use, distribution, and reproduction in any medium, provided the original work is properly cited.

\begin{abstract}
Random surface roughness of bridge deck pavement just like random road surface roughness was simulated by the harmony superposition method in this paper. The dynamic load of vehicle was calculated by the random surface roughness of the deck pavement and the quarter-car model. A finite element model of a box girder bridge and its deck pavement was established, and the bonding condition between the adjacent layers was assumed to be contact bonding condition. The stress values of the asphalt concrete layer were calculated and analyzed when surface roughness condition, vehicle speed, and disengaging area changed. Results show that random surface roughness of deck pavement affected the stress trend of the asphalt concrete layer obviously. The appearance of disengaging area would increase the stress values of the asphalt concrete layer and the normal tensile stress value between the asphalt concrete layer and the waterproof layer. This would speed up the damage of the asphalt concrete layer and enlarge further the disengaging area.
\end{abstract}

\section{Introduction}

When a vehicle passes through asphalt concrete bridge deck pavement, vehicle vibration was excited due to surface roughness of the asphalt concrete bridge deck pavement. Additional dynamic loads $[1,2]$ were produced in the process of the vehicle movement because of surface roughness, which would give rise to stress increase of the asphalt concrete bridge deck pavement and exacerbate the damage of asphalt concrete bridge deck pavement. Furthermore, surface roughness of the pavement has a significant influence on driving comfort and driving safety [3]. Many researchers [4-11] had studied the response of road and bridge deck pavement under the action of dead loads, moving constant loads, and dynamic loads, and dynamic loads have been considered to be a better way to reflect surface roughness of road and bridge deck pavement. White noise filtering method, harmony superposition method, FFT method, and AR/ARMA method are four common types of models to produce surface roughness of road and bridge deck pavement, in which harmony superposition method and FFT method $[12,13]$ are considered to be simple, highly accurate in computation, and based on rigorous mathematical foundation.

It is well known that asphalt concrete bridge deck pavement is multilayered composite system; thus, bonding condition between adjacent layers affects stress transmission and energy dissipation of bridge deck pavement structure. However, most previous researchers [14-18] assumed that the bonding condition between adjacent layers was full-bond and no sliding, and a few of them even assumed that the bonding condition between adjacent layers was no-bond. In fact, many researchers [19-22] agreed that the bonding condition between adjacent layers are not the two extreme conditions, and the real interlayer bonding condition lies somewhere between full-bond condition and no-bond condition. Therefore, there is a need to develop an interlayer bonding model of asphalt concrete bridge deck pavement to accurately predict the responses of asphalt concrete bridge deck pavement.

In this study, a box girder bridge and its asphalt concrete deck pavement were established by the ANSYS software. An interlayer contact model of asphalt concrete bridge deck pavement was constructed to obtain a more realistic and 


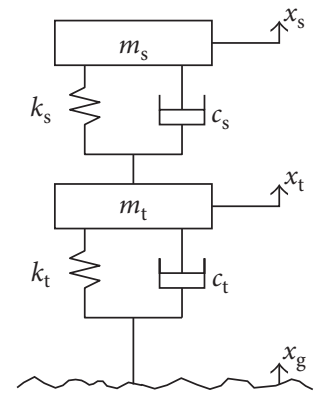

Figure 1: A quarter-car model.

effective method to embody the interlayer bonding condition. Using the interlayer contact model, the extreme stress of the asphalt concrete layer was calculated by the ANSYS software under dynamic load of vehicle. The effect of surface roughness of asphalt concrete layer, vehicle speed, and bonding failure on stress value of the asphalt concrete layer were studied and analyzed.

\section{Computing Method and Theory}

2.1. Mathematical Model for a Quarter-Car. A quarter-car model as shown in Figure 1 is a classic vehicle vibration model in dynamical model, and it is effective for simulating dynamic load of vehicle. In the quarter-car model, the suspended mass is denoted by $m_{\mathrm{s}}$ and the mass of wheel is denoted by $m_{\mathrm{t}}$. Their vertical displacements are denoted by $x_{\mathrm{s}}$ and $x_{\mathrm{t}}$, respectively. The suspension stiffness and the tire stiffness are represented by $k_{\mathrm{s}}$ and $k_{\mathrm{t}}$, respectively, and their damping is represented by $c_{s}$ and $c_{t}$, respectively. The random surface roughness of the bridge deck pavement is a stochastic process denoted by $x_{\mathrm{g}}$.

The equations of motion of the quarter-car model can be written as follows [23, 24]:

$$
\begin{aligned}
& m_{\mathrm{s}} \ddot{x}_{\mathrm{s}}=-k_{\mathrm{s}}\left(x_{\mathrm{s}}-x_{\mathrm{t}}\right)-c_{\mathrm{s}}\left(\dot{x}_{\mathrm{s}}-\dot{x}_{\mathrm{t}}\right), \\
& m_{\mathrm{t}} \ddot{x}_{\mathrm{t}}=k_{\mathrm{s}}\left(x_{\mathrm{s}}-x_{\mathrm{t}}\right)+c_{\mathrm{s}}\left(\dot{x}_{\mathrm{s}}-\dot{x}_{\mathrm{t}}\right)-k_{\mathrm{t}}\left(x_{\mathrm{t}}-x_{\mathrm{g}}\right)-c_{\mathrm{t}}\left(\dot{x}_{\mathrm{s}}-\dot{x}_{\mathrm{g}}\right) .
\end{aligned}
$$

The dynamic load of vehicle acting on the bridge deck pavement is denoted by $F_{\mathrm{t}}$, which is represented as follows:

$$
\begin{aligned}
& F_{\mathrm{t}}=F_{\mathrm{d}}+F_{\mathrm{m}}, \\
& F_{\mathrm{d}}=k_{\mathrm{t}}\left(x_{\mathrm{t}}-x_{\mathrm{g}}\right)+c_{\mathrm{t}}\left(\dot{x}_{\mathrm{t}}-\dot{x}_{\mathrm{g}}\right), \\
& F_{\mathrm{m}}=\left(m_{\mathrm{s}}+m_{\mathrm{t}}\right) g,
\end{aligned}
$$

where $g$ is the acceleration of gravity, $F_{d}$ is the additional dynamic load, and the parameters used for the quarter-car model are listed in Table 1 [24].

2.2. Simulation of Random Road Surface Roughness. The random surface roughness $x_{\mathrm{g}}$ of asphalt concrete bridge deck pavement can be described by a zero-mean, realvalued, and stationary Gaussian process. In the researches $[4,23], x_{\mathrm{g}}$ can be expressed as
TABLE 1: Parameters of the quarter-car model.

\begin{tabular}{lcccccc}
\hline Parameters & $\begin{array}{c}m_{\mathrm{s}} \\
(\mathrm{kg})\end{array}$ & $\begin{array}{c}m_{\mathrm{t}} \\
(\mathrm{kg})\end{array}$ & $\begin{array}{c}k_{\mathrm{s}} \\
(\mathrm{N} / \mathrm{m})\end{array}$ & $\begin{array}{c}k_{\mathrm{t}} \\
(\mathrm{N} / \mathrm{m})\end{array}$ & $\begin{array}{c}c_{\mathrm{s}} \\
(\mathrm{N} \cdot \mathrm{s} / \mathrm{m})\end{array}$ & $\begin{array}{c}c_{\mathrm{t}} \\
(\mathrm{N} \cdot \mathrm{s} / \mathrm{m})\end{array}$ \\
\hline Value & 4450 & 550 & $1 \times 10^{6}$ & $1.5 \times 10^{4}$ & $1.75 \times 10^{6}$ & $2 \times 10^{3}$ \\
\hline
\end{tabular}

TABLE 2: Estimation scale of surface roughness condition of bridge deck pavement.

\begin{tabular}{lccccc}
\hline Condition & Very good & Good & Average & Poor & Very poor \\
\hline IRI value & 0 & 2 & 4 or 6 & 8 & 10 \\
\hline
\end{tabular}

IRI $=0$ means an absolutely smooth longitudinal surface; IRI $=2$ means a good surface condition; IRI $=6$ means a moderately rough surface; $\mathrm{IRI}=10$ means a highly rough surface.

$$
x_{\mathrm{g}}(t)=\sum_{k=1}^{N} A_{k} \cos \left(\omega_{k} t+\phi_{k}\right)
$$

where $\phi_{k}(k=1,2,3, \ldots, N)$ are independent random phase angles with uniformly distributed in the range $[0,2 \pi] . N$ is the total number of terms used to build up the road surface roughness. $\omega_{k}$ is computed by

$$
\begin{aligned}
& \omega_{k}=2 \pi v n_{k}, \\
& n_{k}=n_{1}+k \Delta n(k=1,2,3, \ldots, N), \\
& \Delta n=\frac{\left(n_{\mathrm{r}}-n_{1}\right)}{N},
\end{aligned}
$$

where $n_{k}$ is the spatial frequency within the interval $\left[n_{\mathrm{l}}, n_{\mathrm{r}}\right]$. $n_{1}$ and $n_{\mathrm{r}}$ are the lower and upper cut-off spatial frequencies $\left(\mathrm{m}^{-1}\right)$, respectively. $v$ is a constant vehicle speed. $A_{k}$ is computed by

$$
A_{k}^{2}=4 G_{\mathrm{d}}\left(n_{k}\right) \Delta n(k=1,2,3, \ldots, N),
$$

where $G_{\mathrm{d}}(n)$ is the power spectral density function, according to the research, which can be expressed as [23]

$$
G_{\mathrm{d}}(n)= \begin{cases}1.63 K_{0}\left(\frac{n}{n_{0}}\right)^{-2} \mathrm{IRI}^{2}, & \text { for } n_{\mathrm{l}} \leq n \leq n_{\mathrm{r}} \\ 0, & \text { elsewhere, }\end{cases}
$$

where $K_{0}=10^{-6}\left(\mathrm{~m}^{3}\right), n_{0}=0.1\left(\mathrm{~m}^{-1}\right)$. IRI is the international roughness index $(\mathrm{m} / \mathrm{km})$. According to Paterson's research [25], the surface roughness condition of bridge deck pavement can be divided into six degrees, and its values are listed in Table 2.

2.3. Interlayer Contact Model. For simulating the real interlayer bonding condition, the bonding condition between adjacent layers was assumed to be contact bonding condition [26]. The concept of interlayer contact model can be illustrated in Figure 2. In the interlayer contact model, the bottom of asphalt concrete layer and the top of waterproof layer are covered with contact element and target element, respectively, and contact element and target element are 


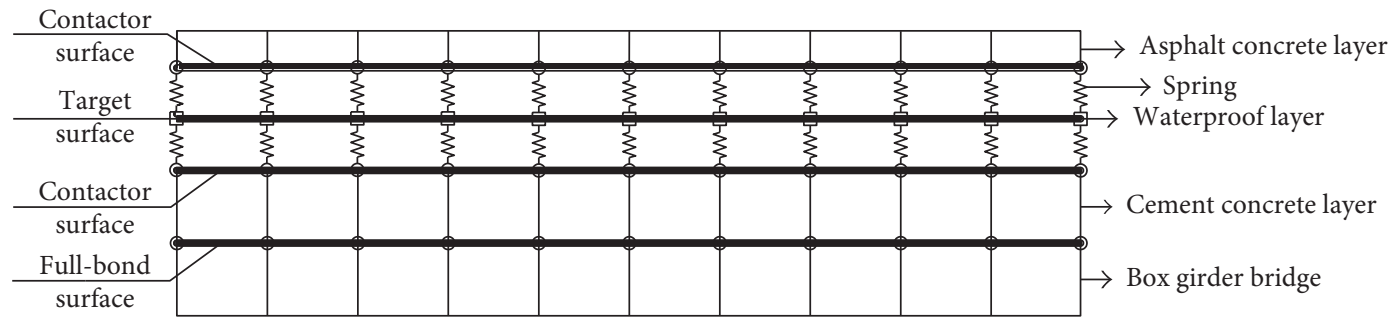

Figure 2: Modeling for contact bonding condition.

connected by translational spring element at the corresponding nodes. The bottom of waterproof layer and the top of cement concrete layer are covered with target element and contact element, respectively, and contact element and target element are also connected by translational spring element at the corresponding nodes. The bonding condition between the cement concrete layer and the box girder bridge is assumed to be full-bond condition.

The contact bonding condition is different from the fullbond condition and the no-bond condition. In the contact bonding condition, the stress transfer between contactor surface and target surface is nonlinear. The springs between the contactor surface and the target surface are used to measure the compression length, and the compression length will be used to calculate the stress at the corresponding nodes according to contact algorithm [27]. The contact algorithm has the characteristic of highly nonlinearity and conducted and completed by iterative calculation. In elastic model, there are the same stress and strain at the corresponding nodes. In the interlayer contact model, the stress and strain at the corresponding nodes are calculated by the contact algorithm.

In the interlayer contact model, the shear stress transfer between the adjacent layers follows the Coulomb friction model [27]:

$$
\begin{gathered}
\tau_{\lim }=\mu P+b, \\
|\tau| \leq \tau_{\text {lim }},
\end{gathered}
$$

where $\tau_{\text {lim }}$ is ultimate shear stress, $\mu$ is the sliding friction coefficient, and it equals 0.5 in this paper, $P$ is the contact compressive stress in normal direction, $b$ is the cohesion between the adjacent layer, and $\tau$ is the equivalent shear stress. In (9), if $\mu$ equals 0 or $P$ equals 0 , the cohesion $b$ still exists; however, if $b$ equals 0 , two adjacent layers show cohesive failure. In (10), when $|\tau|$ between two adjacent layers is less than or equal $\tau_{\text {lim }}$, the two layers keep sticking, or the two layers start to slide.

As vehicle load chronically and repeatedly acted on the asphalt concrete deck pavement, disengaging area (bonding failure) might occur between the adjacent layers. If disengaging area existed between the adjacent layers, the cohesion $b$ there was assumed to be 0 in the interlayer contact model. Five types of disengaging area are shown in Figure 3, where the dashed box represents the load position on the asphalt concrete surface, and the shaded area means the disengaging area between the asphalt concrete

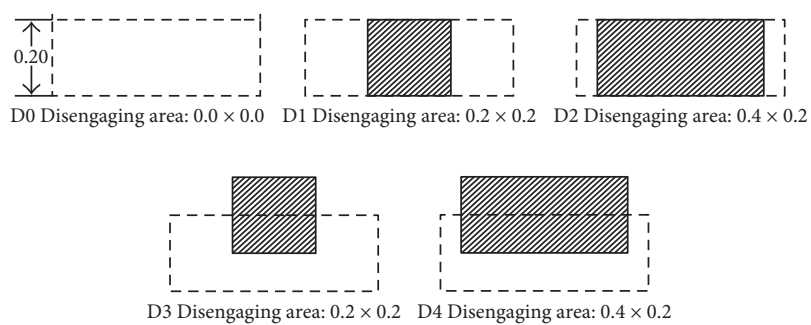

FIgURe 3: Type of disengaging area under loading position (unit: $\mathrm{m}^{2}$ ).

layer and the waterproof layer. The disengaging area in type "D0" was none, which means that there is no disengaging area between the asphalt concrete layer and the waterproof layer.

2.4. Computing Model and Simulation of Dynamic Load of Vehicle. In this paper, a box girder bridge with a length of 20 meters and its asphalt concrete bridge deck pavement were established by the ANSYS software, and their cross section size is shown in Figure 4. The asphalt concrete surface layer, the cement concrete layer, and the box girder bridge were simulated by solid 45 element, and the waterproof layer was simulated by shell41 element. The surface layer was subjected to double-wheel load of $50 \mathrm{kN}$, and the tire ground contact area is $0.5 \mathrm{~m} \times 0.2 \mathrm{~m}$. The driving direction was the same with the direction of $z$-axis, and the dynamic load of vehicle moved from one end of the bridge to the other end of the bridge. The load moved forward $0.2 \mathrm{~m}$ in each iteration step. The parameters used for the finite element computing model are listed in Table 3, and the bonding condition between adjacent layers was assumed to be the contact bonding condition as shown in Figure 2.

In this study, the parameters $n_{\mathrm{l}}$ and $n_{\mathrm{r}}$ are equal to 0.13 and 2.83, respectively, and the parameter $N$ is equal to 100 . Firstly, the values of the surface roughness of bridge deck pavement $x_{\mathrm{g}}$ were simulated by the MATLAB software according to (5). Then, (1) was solved, the values of additional load $F_{\mathrm{d}}$ were obtained according to (3), and the values of dynamic load $F_{\mathrm{t}}$ were obtained according to (2). Finally, for $I R I=2,6$, and 10 , simulation of dynamic load of vehicle under different vehicle speed is shown in Figures 5-7, respectively. According to these figures, when vehicle speed increased, the extreme value of dynamic load of vehicle also increased under a certain IRI. When IRI increased, the extreme value of dynamic load of vehicle also increased under a certain vehicle speed. 


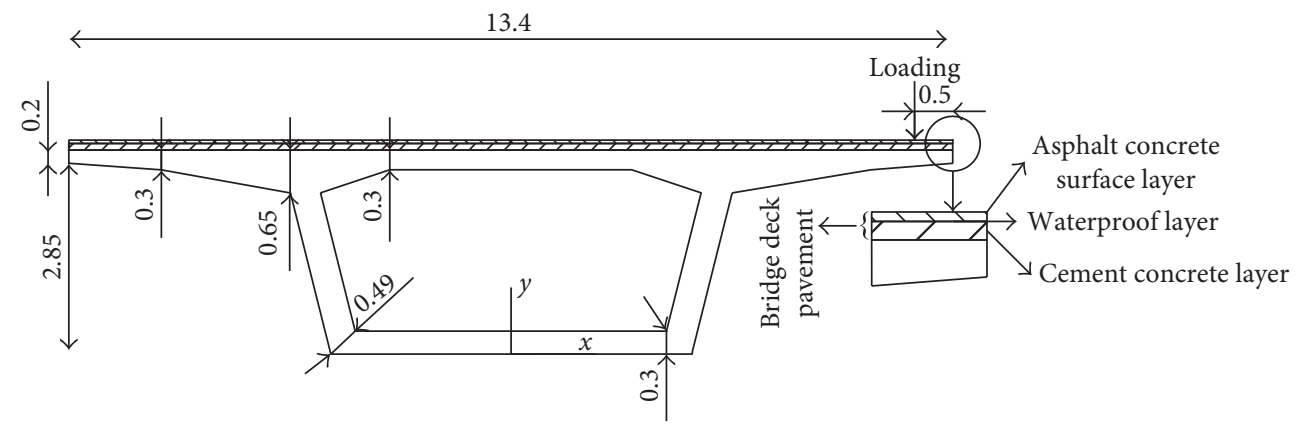

FIgURE 4: Cross section of box girder bridge (unit: m).

TABLe 3: Parameters for the finite element computing model.

\begin{tabular}{lccc}
\hline & Elastic modulus $(\mathrm{GPa})$ & Thickness $(\mathrm{m})$ & Poisson's ratio \\
\hline Asphalt concrete layer & 1.20 & 0.080 & 0.25 \\
Waterproof layer & 0.15 & 0.002 & 0.30 \\
Cement concrete layer & 30.00 & 0.080 & 0.15 \\
Box girder bridge & 36.00 & - & 0.15 \\
\hline
\end{tabular}

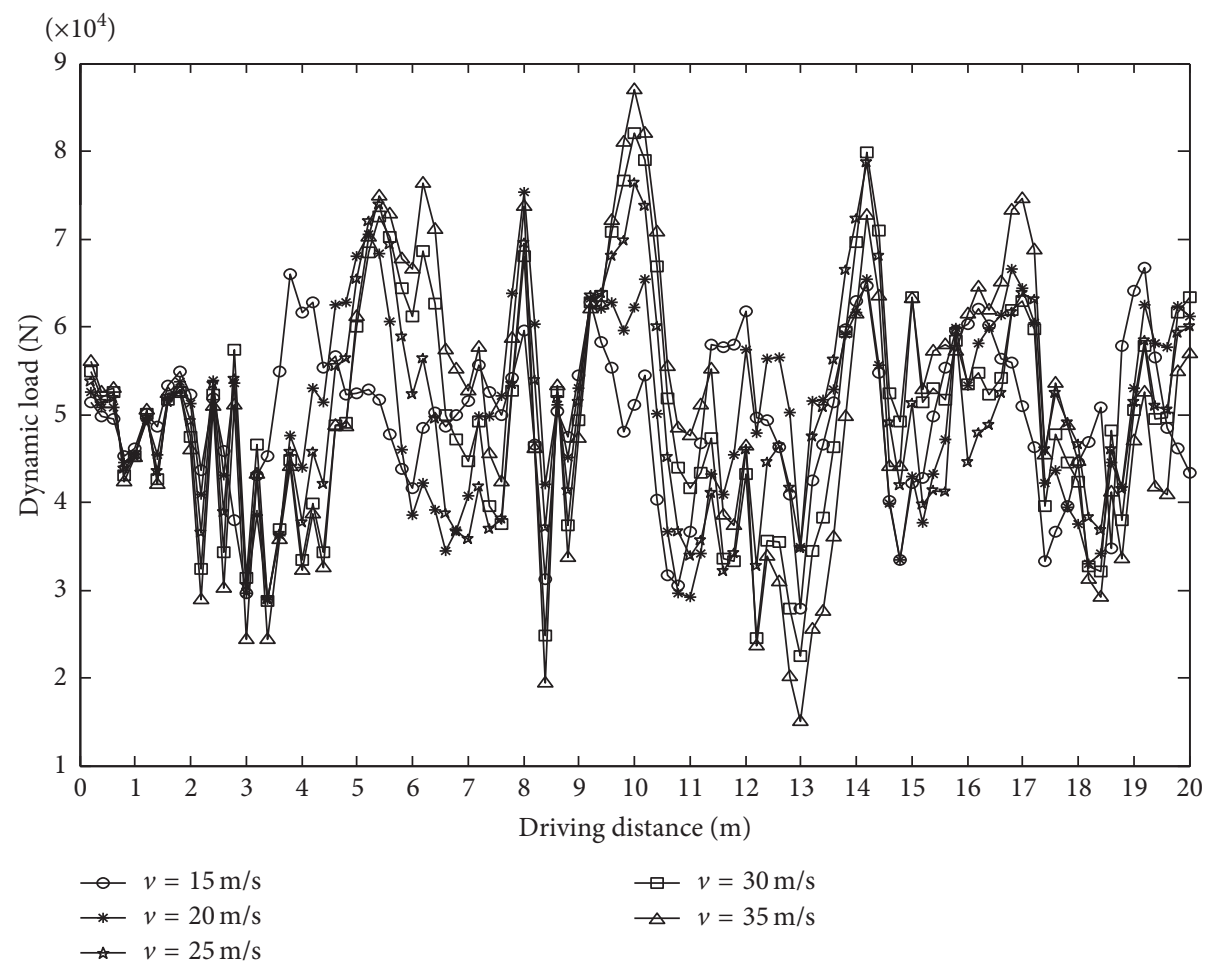

FIgURE 5: Simulation of dynamic load of vehicle when IRI $=2$.

Built the interlayer contact model by the finite element software ANSYS and input the values of $F_{\mathrm{t}}$ at every iteration as the vehicle load move forward. When all the iterations were conducted completely, the maximum stresses of the asphalt concrete layer were obtained by the ANSYS software. In this paper, the maximum transverse tensile stress $\sigma_{x \max }$, the maximum longitudinal tensile stress $\sigma_{z \max }$, the maximum transverse shear stress $\tau_{x y \max }$, and the maximum longitudinal shear stress $\tau_{y z \max }$ of the asphalt concrete layer would be calculated by the ANSYS software for analyzing the stress of asphalt concrete layer and slide between adjacent layers, and the maximum normal tensile stress $\sigma_{y \max }$ 


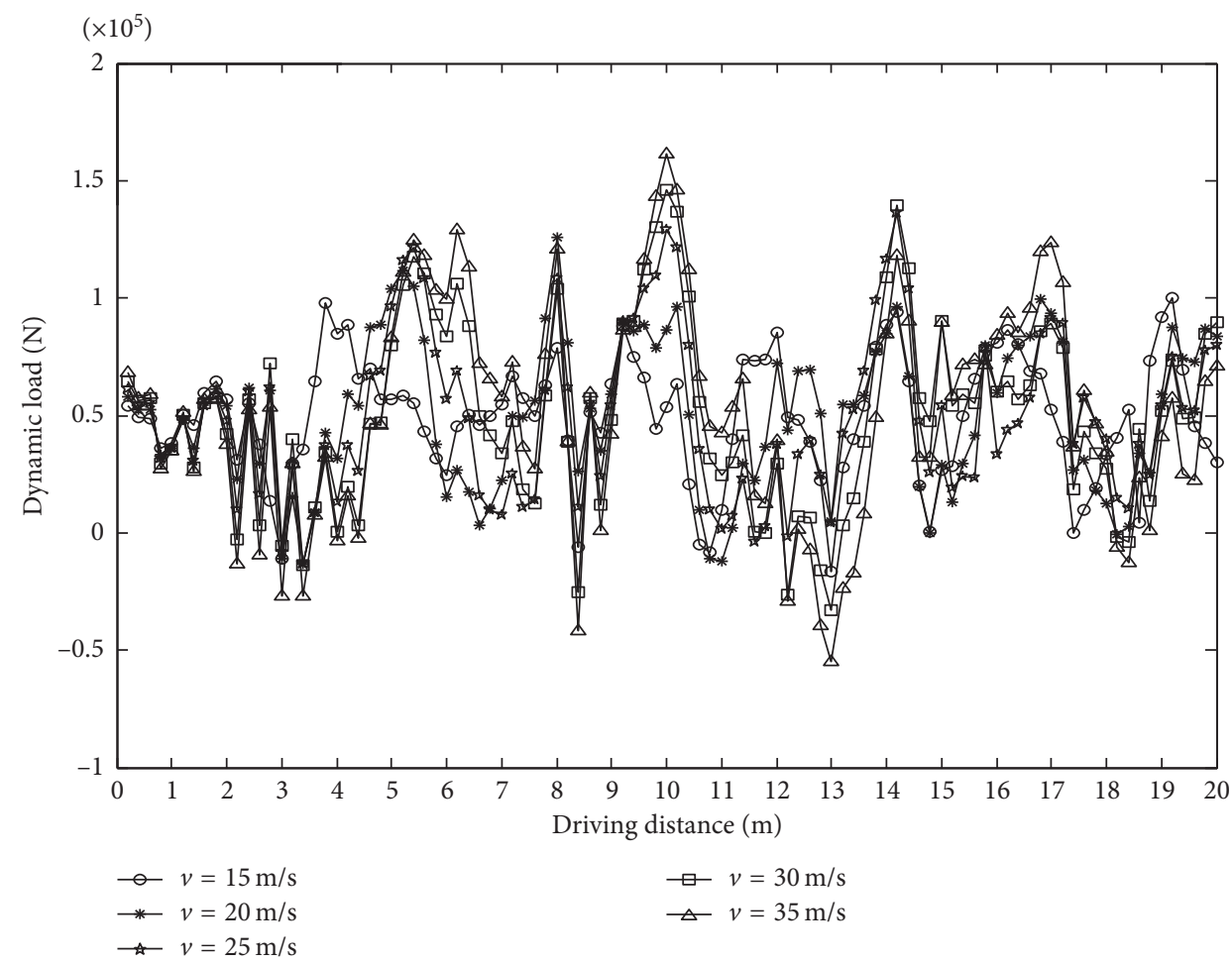

FIGURE 6: Simulation of dynamic load of vehicle when IRI $=6$.

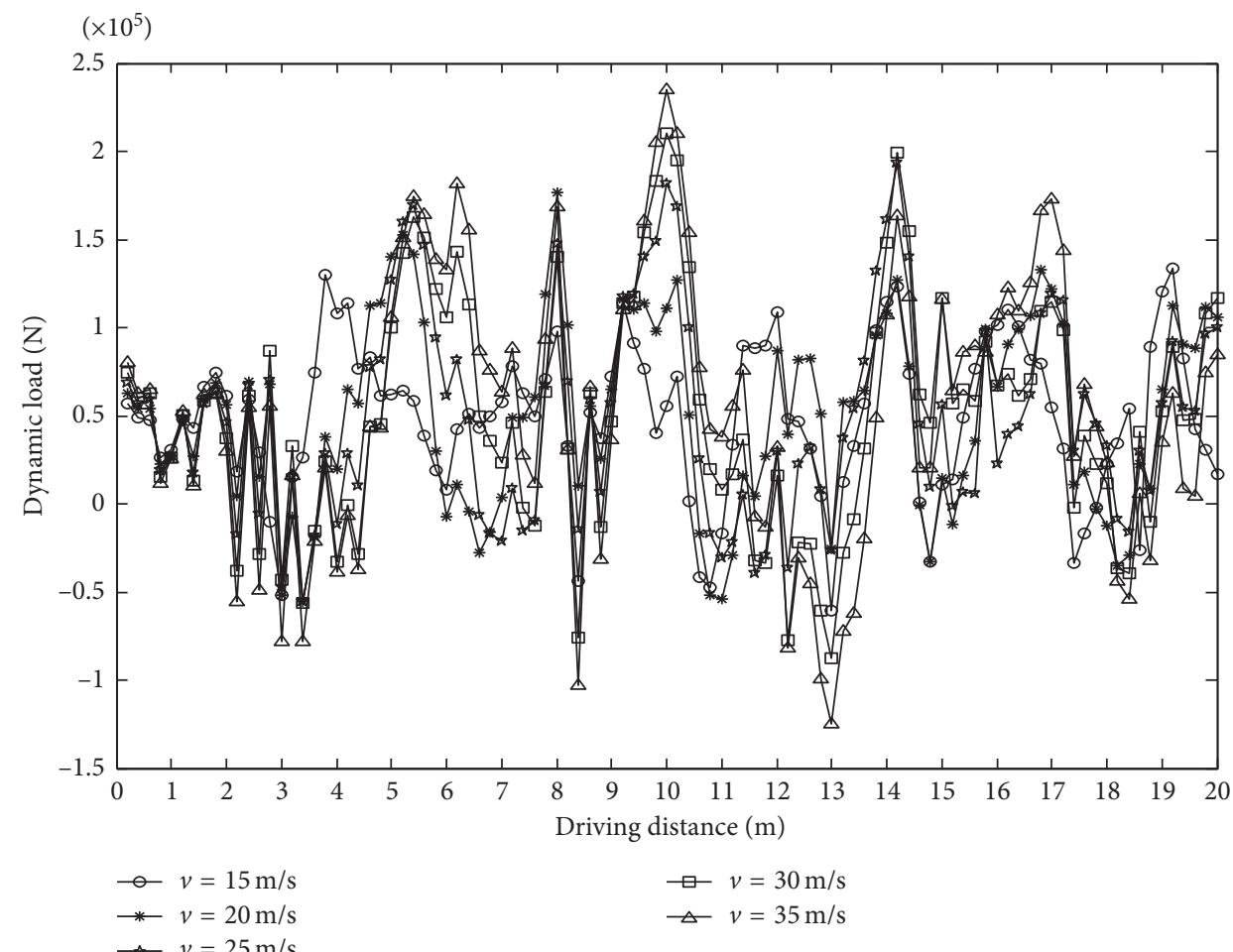

Figure 7: Simulation of dynamic load of vehicle when IRI $=10$. 


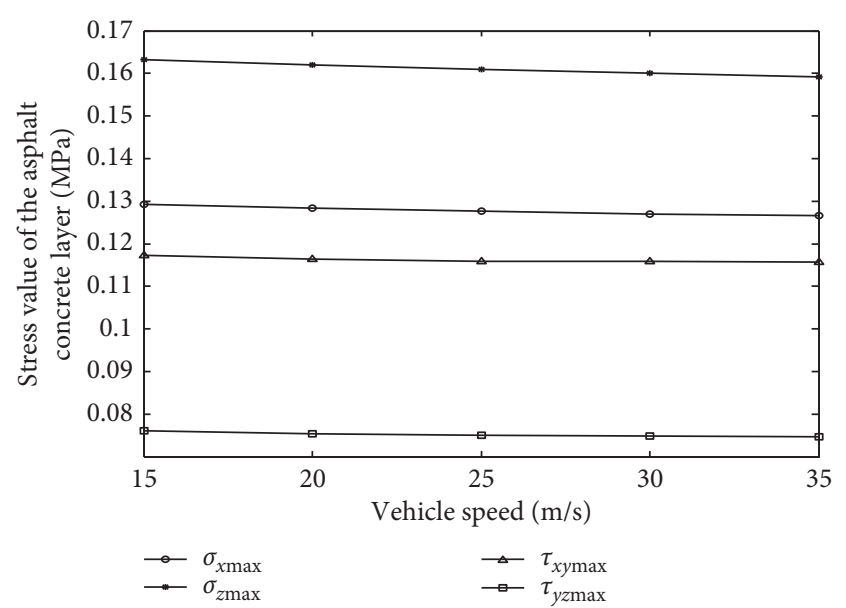

FIGURE 8: Stress values of the asphalt concrete layer when IRI $=0$.

between the asphalt concrete layer and the waterproof layer would also be calculated by the ANSYS software.

\section{Stress Calculation and Analysis for Asphalt Concrete Deck Pavement}

3.1. Influence of IRI and Vehicle Speed on Stress of the Asphalt Concrete Layer. Stress value of the asphalt concrete layer which was calculated by the contact bonding model is shown in Figure 8 under different vehicle speeds when $I R I=0$. When the vehicle speed increased from $15 \mathrm{~m} / \mathrm{s}$ to $35 \mathrm{~m} / \mathrm{s}$, the maximum transverse tensile stress $\sigma_{x \max }$ of the asphalt concrete layer decreased by $1.97 \%$, the maximum longitudinal tensile stress $\sigma_{z \max }$ of the asphalt concrete layer decreased by $2.49 \%$, the maximum transverse shear stress $\tau_{x y \max }$ of the asphalt concrete layer decreased by $1.32 \%$, and the maximum longitudinal shear stress $\tau_{y z \max }$ of the asphalt concrete layer all decreased by $1.92 \%$. This means that the stress value of the asphalt concrete layer would gradually decrease without consideration of the surface roughness of bridge deck pavement when rising driving speed gradually.

Stress value of the asphalt concrete layer which was calculated by the contact bonding model is shown in Figure 9 under different vehicle speeds when IRI $=2$. When the vehicle speed increased from $15 \mathrm{~m} / \mathrm{s}$ to $35 \mathrm{~m} / \mathrm{s}$, the maximum transverse tensile stress $\sigma_{x \max }$ of the asphalt concrete layer increased by $11.48 \%$ and the maximum longitudinal tensile stress $\sigma_{z \max }$, the maximum transverse shear stress $\tau_{x y \max }$, and the maximum longitudinal shear stress $\tau_{y z \max }$ of asphalt concrete layer all increased first and then decreased. When the vehicle speed was $20 \mathrm{~m} / \mathrm{s}$, the maximum longitudinal tensile stress $\sigma_{z \max }$, the maximum transverse shear stress $\tau_{x y \max }$, and the maximum longitudinal shear stress $\tau_{y z \max }$ of the asphalt concrete layer reached their maximum value, respectively. When the vehicle speed increased from $20 \mathrm{~m} / \mathrm{s}$ to $30 \mathrm{~m} / \mathrm{s}$, the maximum longitudinal tensile stress $\sigma_{z \max }$, the maximum transverse shear stress $\tau_{x y \max }$, and the maximum longitudinal shear stress $\tau_{y z \max }$ of the asphalt concrete layer decreased obviously.

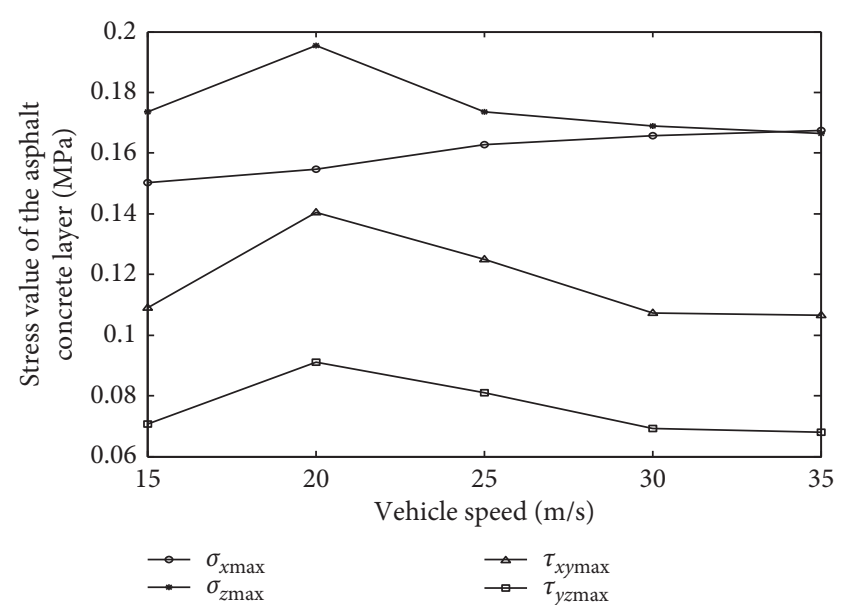

FIGURE 9: Stress values of the asphalt concrete layer when IRI $=2$.

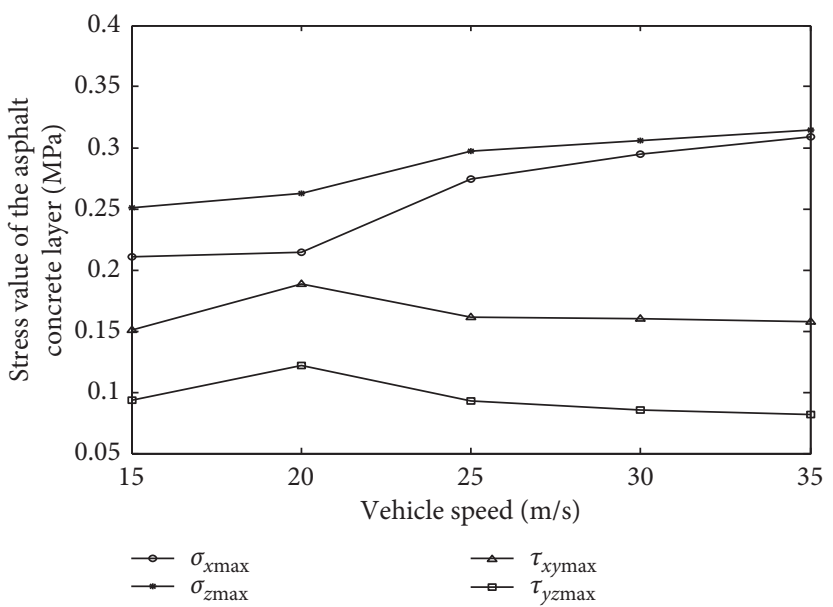

FIGURE 10: Stress values of the asphalt concrete layer when IRI $=6$.

Compared with Figures 8 and 9, the maximum tensile stress value of the asphalt concrete layer when IRI $=2$ was bigger than the maximum tensile stress value of the asphalt concrete layer when IRI $=0$ under the same vehicle speed. Stress trend of asphalt concreter layer when IRI $=2$ was different from stress trend of asphalt concreter layer when IRI $=0$ with consideration of the road surface roughness.

Stress value of asphalt concrete layer which was calculated by the contact bonding model is shown in Figure 10 under different vehicle speeds when IRI $=6$. When the vehicle speed increased from $15 \mathrm{~m} / \mathrm{s}$ to $35 \mathrm{~m} / \mathrm{s}$, the maximum transverse tensile stress $\sigma_{x \max }$ of asphalt concrete layer increased by $46.48 \%$, the maximum longitudinal tensile stress $\sigma_{z \max }$ of asphalt concrete layer increased by $25.37 \%$, and the maximum transverse shear stress $\tau_{x y \max }$ and the maximum longitudinal shear stress $\tau_{y z \max }$ of asphalt concrete layer all increased first and then decreased. When the vehicle speed was $20 \mathrm{~m} / \mathrm{s}$, the maximum transverse shear stress $\tau_{x y \max }$ and the maximum longitudinal shear stress $\tau_{y z \max }$ of asphalt concrete layer reached their maximum value, respectively. 


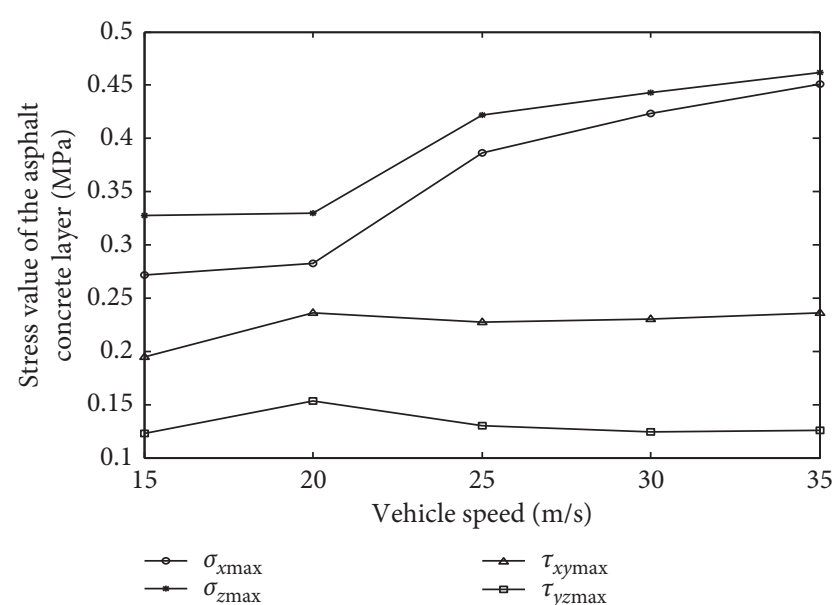

FIGURE 11: Stress values of the asphalt concrete layer when IRI $=10$.

When the vehicle speed increased from $20 \mathrm{~m} / \mathrm{s}$ to $25 \mathrm{~m} / \mathrm{s}$, the maximum transverse tensile stress $\sigma_{x \max }$ and the maximum longitudinal tensile stress $\sigma_{z \max }$ of asphalt concrete layer increased obviously and the maximum transverse shear stress $\tau_{x y \max }$ and the maximum longitudinal shear stress $\tau_{y z \max }$ of asphalt concrete layer decreased obviously. When vehicle speed increased from $25 \mathrm{~m} / \mathrm{s}$ to $35 \mathrm{~m} / \mathrm{s}$, the maximum transverse tensile stress $\sigma_{x \max }$ and the maximum longitudinal tensile stress $\sigma_{z \max }$ of asphalt concrete layer increased slowly and the maximum transverse shear stress $\tau_{x y \max }$ and the maximum longitudinal shear stress $\tau_{y z \max }$ of asphalt concrete layer decreased slowly. Compared with Figures 9 and 10, the maximum tensile/shear stress value of the asphalt concrete layer when IRI $=6$ was bigger than the maximum tensile/shear stress value of the asphalt concrete layer when $I R I=2$ under the same vehicle speed. The maximum shear stress trend of asphalt concreter layer when IRI = 6 was same with the maximum shear stress trend of asphalt concreter layer when $I R I=2$.

Stress value of asphalt concrete layer which was calculated by the contact bonding model is shown in Figure 11 under different vehicle speeds when IRI $=10$. When the vehicle speed increased from $15 \mathrm{~m} / \mathrm{s}$ to $35 \mathrm{~m} / \mathrm{s}$, the maximum transverse tensile stress $\sigma_{x \max }$ of asphalt concrete layer increased by $65.80 \%$, the maximum longitudinal tensile stress $\sigma_{z \max }$ of asphalt concrete layer increased by $40.77 \%$, and the maximum transverse shear stress $\tau_{x y \max }$ and the maximum longitudinal shear stress $\tau_{y z \max }$ of asphalt concrete layer all increased firstly, then decreased, and finally increased. When the vehicle speed was $20 \mathrm{~m} / \mathrm{s}$, the maximum transverse shear stress $\tau_{x y \max }$ and the maximum longitudinal shear stress $\tau_{y z \max }$ of asphalt concrete layer reached their maximum value, respectively. When vehicle speed increased from $20 \mathrm{~m} / \mathrm{s}$ to $25 \mathrm{~m} / \mathrm{s}$, the maximum transverse tensile stress $\sigma_{x \max }$ and the maximum longitudinal tensile stress $\sigma_{z \max }$ of asphalt concrete layer increased obviously. When vehicle speed increased from $25 \mathrm{~m} / \mathrm{s}$ to $35 \mathrm{~m} / \mathrm{s}$, the maximum transverse tensile stress $\sigma_{x \max }$ and the maximum longitudinal tensile stress $\sigma_{z \max }$ of asphalt concrete layer increased gradually and the maximum transverse shear stress $\tau_{x y \max }$ of asphalt concrete layer increased slowly. Compared with Figures 10 and 11, the maximum tensile/shear stress value of the asphalt concrete layer when IRI $=10$ was bigger than the maximum tensile/shear stress value of the asphalt concrete layer when IRI $=6$ under the same vehicle speed. The maximum tensile stress trend of asphalt concreter layer when IRI $=10$ was same with the maximum tensile stress trend of asphalt concreter layer when IRI $=6$. In summary, when the IRI value increased, the stress values of the asphalt concrete layer all increased. When the IRI value was definite, the maximum tensile stress values of the asphalt concrete layer were bigger than the maximum tensile stress values of the asphalt concrete layer at the same vehicle speed.

\subsection{Stress of the Asphalt Concrete Layer When Disengaging} Area Existing. Assumed that IRI $=2$ and the vehicle speed was $25 \mathrm{~m} / \mathrm{s}$, the dynamic load of vehicle acted on asphalt concrete surface is shown in Figure 5. When five types of disengaging area as shown in Figure 3 appeared, respectively, between the asphalt concrete layer and the waterproof layer, the stress values of the asphalt concrete layer which were calculated by the contact bonding model are listed in Table 4. Comparing the stress values of the asphalt concrete layer at the type "D0" with the stress values of the asphalt concrete layer at the other type, the maximum transverse tensile stress $\sigma_{x \max }$ and the maximum longitudinal tensile stress $\sigma_{z \max }$ values of the asphalt concrete layer all increased, and the maximum normal tensile stress $\sigma_{y \max }$ values between the asphalt concrete layer and the waterproof layer increased obviously when the type of disengaging area changed from the type "D0" to the type "D1." The maximum transverse shear stress $\tau_{x y \max }$ of the asphalt concrete layer was almost not changed under different types of disengaging area. Except for the maximum transverse shear stress $\tau_{x y \max }$ of the asphalt concrete layer, the other maximum stress values of the asphalt concrete layer all increased with the disengaging area increased. When the disengaging area was same, such as the type "D1" and the type "D3," or the type "D2" and the type "D4," the more the disengaging area under the load was, the bigger the maximum tensile stress values of the asphalt concrete layer was (Table 4). Comparing the stress values of the asphalt concrete layer at the type "D1" with the stress values of the asphalt concrete layer at the type "D4," there were the same disengaging area under the load, but the maximum tensile stress values and the maximum longitudinal shear stress $\tau_{y z \max }$ of asphalt concrete layer at the type "D4" were bigger than the corresponding stress values of the asphalt concrete layer at the type "D1" in Table 4.

Assuming that IRI $=6$ and the vehicle speed was $25 \mathrm{~m} / \mathrm{s}$, the dynamic load of vehicle acted on asphalt concrete surface is shown in Figure 6. When five types of disengaging area as shown in Figure 3 appeared, respectively, between the asphalt concrete layer and the waterproof layer, the stress values of the asphalt concrete layer which were calculated by the contact bonding model are listed in Table 5. Comparing the stress values of the asphalt concrete layer at the type "D0" 
TABLE 4: Stress value of the asphalt concrete layer when IRI $=2$.

\begin{tabular}{lccccc}
\hline & $\sigma_{x \max }(\mathrm{MPa})$ & $\sigma_{y \max }(\mathrm{MPa})$ & $\sigma_{z \max }(\mathrm{MPa})$ & $\tau_{x y \max }(\mathrm{MPa})$ & $\tau_{y z \max }(\mathrm{MPa})$ \\
\hline Type D0 & 0.162697 & 0.051349 & 0.173667 & 0.125011 & 0.080908 \\
Type D1 & 0.200714 & 0.256144 & 0.230054 & 0.125010 & 0.080923 \\
Type D2 & 0.329370 & 0.295752 & 0.343371 & 0.125008 & 0.116269 \\
Type D3 & 0.191053 & 0.255890 & 0.181542 & 0.125008 & 0.080923 \\
Type D4 & 0.276347 & 0.290198 & 0.241429 & 0.103085 \\
\hline
\end{tabular}

TABLE 5: Stress value of the asphalt concrete layer when IRI $=6$.

\begin{tabular}{lccccc}
\hline & $\sigma_{x \max }(\mathrm{MPa})$ & $\sigma_{y \max }(\mathrm{MPa})$ & $\sigma_{z \max }(\mathrm{MPa})$ & $\tau_{x y \max }(\mathrm{MPa})$ & 0.161153 \\
\hline Type D0 & 0.274626 & 0.087097 & 0.297205 & 0.171558 & 0.092727 \\
Type D1 & 0.339848 & 0.430552 & 0.394346 & 0.206075 & 0.126995 \\
Type D2 & 0.556346 & 0.497758 & 0.585864 & 0.190524 & 0.194432 \\
Type D3 & 0.323336 & 0.430185 & 0.312521 & 0.186459 & 0.097266 \\
Type D4 & 0.456856 & 0.479859 & 0.413859 & 0.170920 \\
\hline
\end{tabular}

TABLE 6: Stress value of the asphalt concrete layer when IRI $=10$.

\begin{tabular}{|c|c|c|c|c|c|}
\hline & $\sigma_{x \max }(\mathrm{MPa})$ & $\sigma_{y \max }(\mathrm{MPa})$ & $\sigma_{z \max }(\mathrm{MPa})$ & $\tau_{x y \max }(\mathrm{MPa})$ & $\tau_{y z \max }(\mathrm{MPa})$ \\
\hline Type D0 & 0.386547 & 0.122836 & 0.422160 & 0.227311 & 0.130166 \\
\hline Type D1 & 0.478958 & 0.604918 & 0.558667 & 0.240900 & 0.177892 \\
\hline Type D2 & 0.783280 & 0.699711 & 0.828351 & 0.290451 & 0.272589 \\
\hline Type D3 & 0.455583 & 0.600399 & 0.443535 & 0.266538 & 0.138615 \\
\hline Type D4 & 0.637275 & 0.669413 & 0.586323 & 0.260713 & 0.238741 \\
\hline
\end{tabular}

with the stress values of the asphalt concrete layer at the other type, the maximum stress values of the asphalt concrete layer all increased, and the maximum normal tensile stress $\sigma_{y \max }$ values between the asphalt concrete layer and the waterproof layer increased obviously when the type of disengaging area changed from the type "D0" to the type "D1." Comparing the type "D0," the type "D1," and the type "D2" in Table 5, when the disengaging area increased, the stress values of the asphalt concrete layer increased. When the disengaging area was same, such as the type "D1" and the type "D3," or the type "D2" and the type "D4," the more the disengaging area under the load was, the bigger the maximum tensile stress values of the asphalt concrete layer was (Table 4). Comparing the stress values of the asphalt concrete layer at the type "D1" with the stress values of the asphalt concrete layer at the type "D4," there were the same disengaging area under the load, but the maximum tensile/shear stress values of the asphalt concrete layer at the type "D4" were bigger than the corresponding stress values of the asphalt concrete layer at the type "D1" in Table 5. Comparing the stress values of the asphalt concrete layer in Tables 4 and 5, the stress values of the asphalt concrete layer in Table 5 were bigger than the stress values of the asphalt concrete layer in the Table 4 at the corresponding type of disengaging area.

Assuming that IRI $=10$ and the vehicle speed was $25 \mathrm{~m} / \mathrm{s}$, the dynamic load of vehicle acted on asphalt concrete surface is shown in Figure 7. When five types of disengaging area as shown in Figure 3 appeared, respectively, between the asphalt concrete layer and the waterproof layer, the stress values of the asphalt concrete layer which were calculated by the contact bonding model are listed in Table 6. The stress values of the asphalt concrete layer all increased with the type of the disengaging area increased from the type "D0" to the type "D2," and the maximum normal tensile stress $\sigma_{y \max }$ values between the asphalt concrete layer and the waterproof layer increased obviously when the type of disengaging area changed from the type "D0" to the type "D1." Comparing the stress values of the asphalt concrete layer at the type "D1" with the stress values of the asphalt concrete layer at the type "D4," there was the same disengaging area under the load, but the maximum tensile/shear stress values of the asphalt concrete layer at the type "D4" were bigger than the corresponding stress values of the asphalt concrete layer at the type "D1" in Table 6. Comparing the stress values of the asphalt concrete layer in Tables 5 and 6 , the stress values of the asphalt concrete layer in Table 6 were bigger than the stress values of the asphalt concrete layer in Table 5 at the corresponding type of disengaging area.

In summary, when the disengaging area appeared between the asphalt concrete layer and the waterproof layer, the tensile stress values of the asphalt concrete layer all increased. The more the disengaging area under the vehicle load was, the bigger the stress values of the asphalt concrete layer were. When the disengaging area was the same, the relative position between the disengaging area and the vehicle load affected the stress values of the asphalt concrete layer. The normal tensile stress value between the asphalt concrete layer and the waterproof layer also increased when the disengaging area increased. 


\section{Conclusions}

The stress values of the asphalt concrete layer were calculated and analyzed when surface roughness of bridge deck pavement, vehicle speed, and disengaging area changed under the dynamic load of vehicle when the bonding condition of the adjacent layers was assumed to be the contact bonding condition. The following conclusions can be drawn:

(1) An interlayer contact model of asphalt concrete bridge deck pavement was constructed to obtain a more realistic and effective method to embody the interlayer bonding condition. The interlayer contact model is used for not only concrete bridge deck pavement, but also steel bridge deck pavement. Whether the bonding failure between adjacent layers appears or not, the interlayer contact model can still be used to calculate the stresses of asphalt concrete layer.

(2) The surface roughness of asphalt concrete layer affects the stress values of the asphalt concrete layer. Measures should be taken to prevent the surface roughness of asphalt concrete layer from "Good" to "Very poor" in order to reduce the tensile/shear stress values of the asphalt concrete layer. When the surface roughness of asphalt concrete layer changed from "Good" to "Very poor," vehicle speed must be restricted to abate the additional dynamic load and protect the asphalt concrete layer.

(3) The disengaging area appeared between the asphalt concrete layer and the waterproof layer resulted in the increase of the stress values of asphalt concrete layer, which would accelerate the damage of the asphalt concrete layer and enlarge further the disengaging area. Therefore, bonding strength between adjacent layers must be improved to avoid the appearance of bonding failure.

\section{Data Availability}

The data used to support the findings of this study are available from the corresponding author upon request.

\section{Conflicts of Interest}

The authors declare that they have no conflicts of interest.

\section{Acknowledgments}

This work was supported by the National Natural Science Foundation of China (Grant no. 11601037) and the Youth Project of National Natural Science Fund (no. 11401045).

\section{References}

[1] Y. W. Cao, N. X. Liang, and J. P. Xu, "Calculation of pavement evenness under dynamic load of moving vehicle," Journal of Chang'an University, vol. 24, no. 4, pp. 22-25, 2004.
[2] Z. D. Qian, Y. Liu, and W. Huang, "Analysis of the dynamic response of steel-deck pavement with roughness," China Civil Engineering Journal, vol. 40, no. 4, pp. 49-53, 2007.

[3] H. Y. Li, S. P. Yang, and S. H. Li, "Dynamical analysis of an asphalt pavement due to vehicle-road interaction," Journal of Vibration and Shock, vol. 28, no. 4, pp. 86-89, 2009.

[4] F. T. K. Au, Y. S. Cheng, and Y. K. Cheung, "Effects of random road surface roughness and long-term deflection of prestressed concrete girder and cable-stayed bridges on impact due to moving vehicles," Computers and Structures, vol. 79, no. 8, pp. 853-872, 2001.

[5] T. J. Chen, Z. D. Qian, and W. Huang, "Analysis of dynamic response of deck pavement for large-span steel bridge," Journal of Highway and Transportation Research and Development, vol. 25, no. 5, pp. 68-72, 2008.

[6] D. W. Liu, G. Z. Li, H. M. Chen et al., "Dynamic response of pavement based on random dynamic load of vehicle," Transactions of the Chinese Society of Agricultural Machinery, vol. 24, no. 2, pp. 28-33, 2011.

[7] W. Schiehlen and B. Hu, "Spectral simulation and shock absorber identification," International Journal of Non-Linear Mechanics, vol. 38, no. 2, pp. 161-171, 2003.

[8] J. S. Shan, X. M. Huang, and G. Y. Liao, "Dynamic response analysis of pavement structure under moving load," Journal of Highway and Transportation Research and Development, vol. 24, no. 1, pp. 10-13, 2007.

[9] J. M. Wu, J. P. Liang, and S. Adhikari, "Dynamic response of concrete pavement structure with asphalt isolating layer under moving loads," Journal of Traffic and Transportation Engineering, vol. 1, no. 6, pp. 439-447, 2014.

[10] W. Xu, G. L. Zheng, and X. N. Zhang, "Stress sensitive analysis of concrete deck asphalt overlay," Journal of Highway and Transportation Research and Development, vol. 21, no. 1, pp. 8-11, 2004.

[11] Q. W. Xu, C. S. Hu, and H. Wang, "Mechanic analysis and design of composite type overlay on concrete bridge pavement," Journal of Chang'an University, vol. 27, no. 4, pp. 28-32, 2007.

[12] J. Peng, J. He, X. H. Li et al., "Simulation comparison and evaluation of common time domain models under road irregularity excitation," Journal of PLA University of Science and Technology, vol. 10, no. 1, pp. 77-82, 2009.

[13] Y. L. Zhang and Y. F. Zhong, "Time domain model of road undulation excitation to vehicles," Transactions of the Chinese Society of Agricultural Machinery, vol. 35, no. 2, pp. 9-12, 2004.

[14] C. F. Ai, Y. J. Qiu, C. Mao et al., "Influence of interlayer conditions on structure responses of asphalt pavement," in Proceedings of the First International Conference on Transportation Engineering, pp. 272-277, Chengdu, China, July 2007.

[15] X. Hu, "Shear stress response analysis of asphalt concrete pavement for concrete bridge deck," Highway Engineering, vol. 32, no. 4, pp. 136-141, 2007.

[16] H. Kim, M. Arraigada, C. Raab et al., "Numerical and experimental analysis for the interlayer behavior of doublelayered asphalt pavement specimens," Journal of Materials in Civil Engineering, vol. 23, no. 1, pp. 12-20, 2012.

[17] M. R. Kruntcheva, A. C. Collop, and N. H. Thom, "Properties of asphalt concrete layer interfaces," American Society of Civil Engineers, vol. 18, no. 3, pp. 467-471, 2006.

[18] N. Li, S. Han, J. T. Yu et al., "Analysis of bridge deck pavement structure interlayer based on different interface form," in Proceedings of the 10th International Conference of Chinese 
Transportation Professionals, pp. 3194-3200, Beijing, China, August 2010.

[19] S. Chun, K. Kim, J. Greene et al., "Evaluation of interlayer bonding condition on structural response characteristics of asphalt pavement using finite element analysis and full-scale field tests," Construction and Building Materials, vol. 96, pp. 307-318, 2015.

[20] F. Wellner and B. Hristov, "Numerically supported experimental determination of the behavior of the interlayer bond in asphalt pavement," Transportation Research Record Journal of the Transportation Research Board, vol. 2506, no. 2506, pp. 116-125, 2015.

[21] J. P. Zhang, S. H. Wu, J. Z. Pel et al., "Analysis of mechanical responses of asphalt pavement interlayers based on shear spring compliance," Journal of Highway and Transportation Research and Development, vol. 8, no. 1, pp. 1-6, 2014.

[22] L. Zhen, I. L. Al-Qadi, S. H. Carpenter et al., "Interface bonding between hot-mix asphalt and various Portland cement concrete surfaces laboratory assessment," Transportation Research Record, vol. 11, no. 2057, pp. 46-53, 2009.

[23] F. Han, H. Wang, D. H. Dan et al., "Dynamic response research of concrete bridge deck pavement with a consideration of roughness," Journal of Tongji University, vol. 45, no. 9, pp. 1284-1289, 2017.

[24] J. H. Li, J. He, and X. H. Li, "Dynamic response of pavement under vehicle random load and moving constant load," Journal of Chang'an University, vol. 35, no. 2, pp. 38-45, 2015.

[25] W. D. Paterson and T. Watanatada, "Relationships between vehicle speed, ride quality, and road roughness," in Measuring Road Roughness and Its Effects on User Cost and Comfort, T. D. Gillespie and M. Sayers, Eds., pp. 89-110, ASTM International, West Conshohocken, PA, USA, 1985.

[26] X. T. Wang, J. H. Feng, H. Wang et al., "Stress analysis of asphalt concrete deck pavement on steel bridge based on burgers model and interlayer contact," in Proceedings of 6th International Conference on Energy and Environmental Protection, pp. 70-77, Zhuhai, China, June 2017.

[27] X. M. Wang, Y. Q. Li, and H. W. Xu, ANSYS Structural Analysis Unit and Application, China Communications Press, Beijing, China, 2011. 


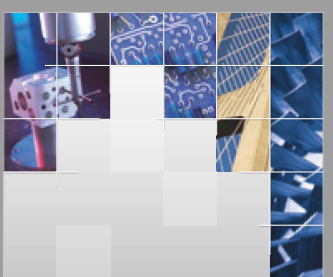

\section{Enfincering}
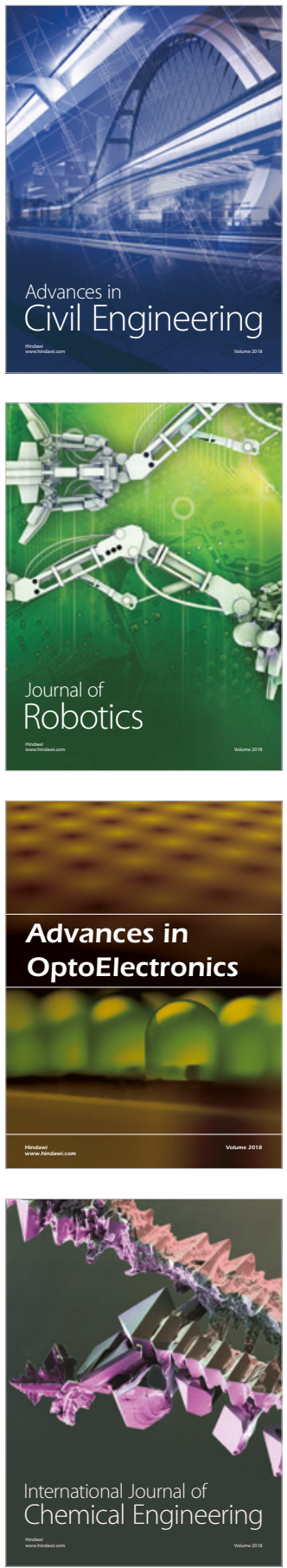

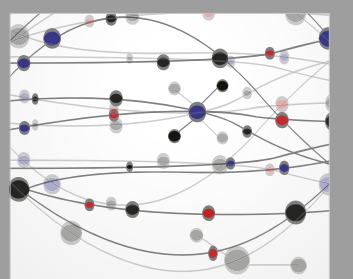

\section{Rotating \\ Machinery}

The Scientific World Journal

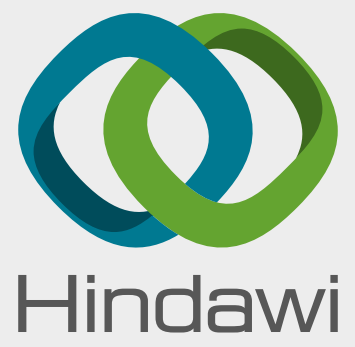

Submit your manuscripts at

www.hindawi.com
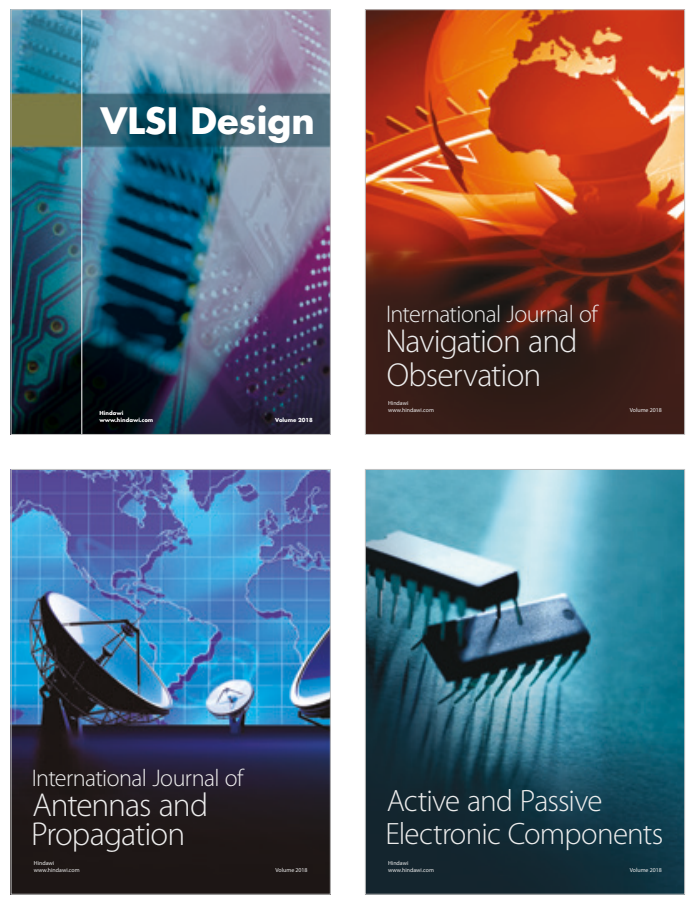
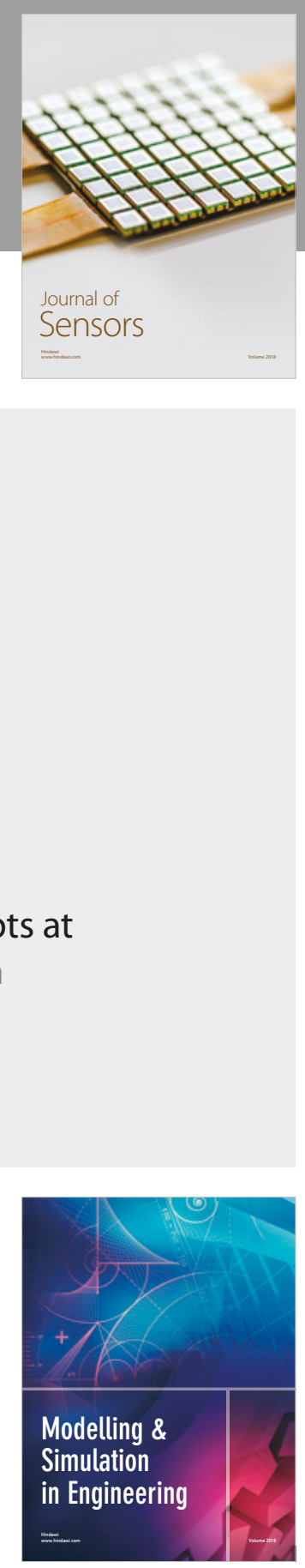

\section{Advances \\ Multimedia}
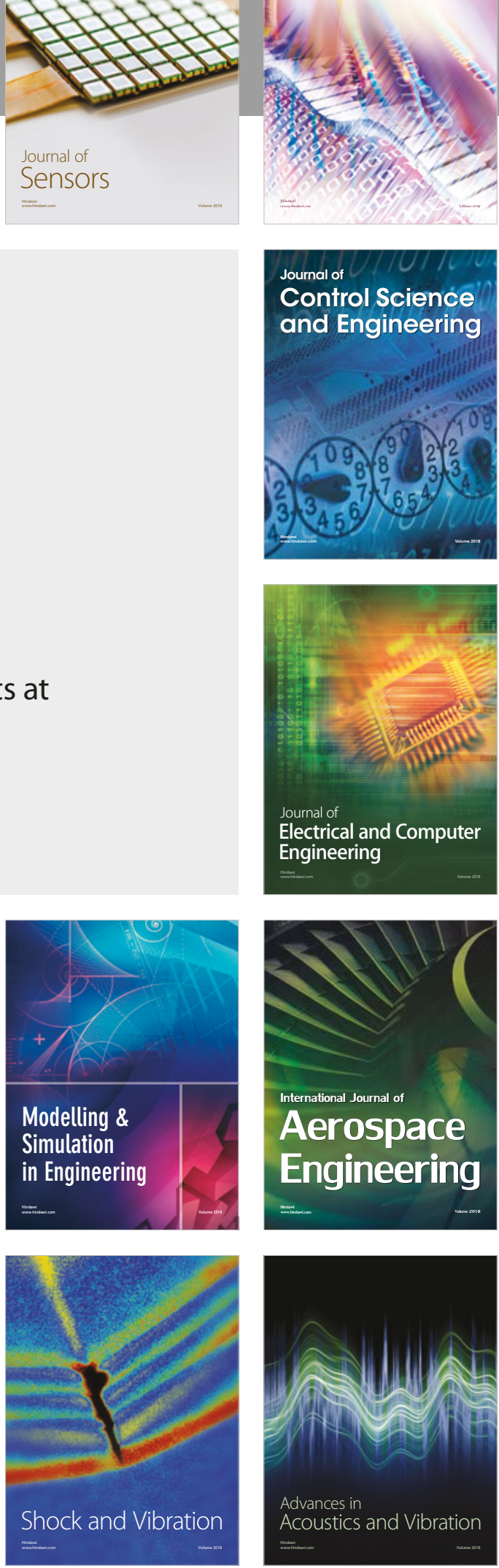